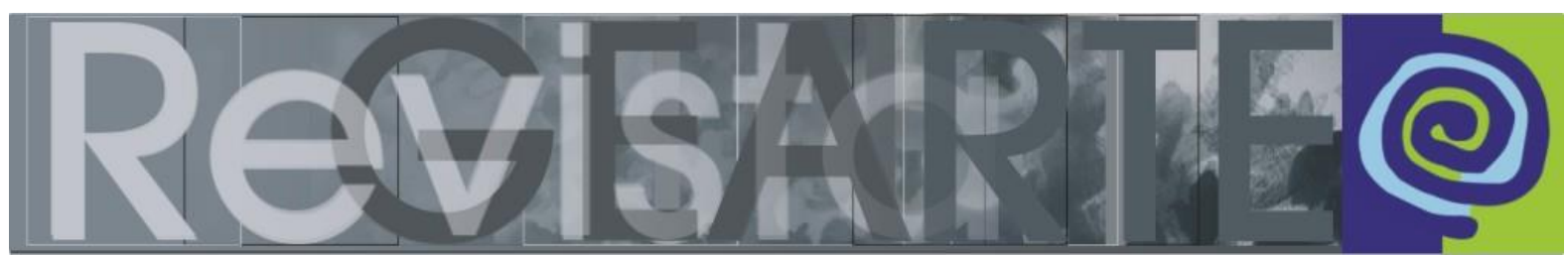

e-ISSN 2357-9854

\title{
Texto literário infantil: produção de sentido a partir do olhar, do brincar e do ler
}

\author{
Marília Forgearini Nunes (Universidade Federal do \\ Rio Grande do Sul — UFRGS, Porto Alegre/RS, Brasil) \\ Tatiana Telch Evalte (Universidade Federal do \\ Rio Grande do Sul — UFRGS, Porto Alegre/RS, Brasil) \\ Analice Dutra Pillar (Universidade Federal do \\ Rio Grande do Sul — UFRGS, Porto Alegre/RS, Brasil)
}

\begin{abstract}
RESUMO - Texto literário infantil: produção de sentido a partir do olhar, do brincar e do ler - O trabalho discute a interação com o texto literário infantil cuja produção gráfica-editorial privilegia e instiga o olhar, o brincar e o ler. Baseado em estudos sobre leitura visual e em pesquisas que tiveram como objeto o livro-brinquedo (EVALTE, 2014) e o livro de imagem (NUNES, 2013), aborda a construção de sentido a partir da interação com esses objetos, explorando suas possibilidades lúdicas e visuais. Analisa um livro-brinquedo e um livro de imagem evidenciando como um olhar sensível e uma vivência lúdica podem ocorrer associados à leitura.
\end{abstract}

PALAVRAS-CHAVE

Produção de sentido. Leitura da imagem. Livro-brinquedo. Livro de imagem.

ABSTRACT - Children's literary text: production of meaning based on looking, playing and reading - This study discusses the interaction with children's literary text, which editorial and graphic production gives privilege and makes possible the actions of reading, playing and looking. We discuss based on researches (NUNES, 2013; EVALTE, 2014) that have as their objects two kinds of editorial and graphic production, the toy book and the wordless book, that investigate the meaning production from the interaction with these objects, exploring their playful and visual possibilities. We present two analyzes, of a toy book and of a wordless book in order to make visible how a more sensible look and the playful experience can take place related to reading.

\section{KEYWORDS}

Meaning production. Image reading. Toy book. Wordless book.

Um dos objetos de leitura mais característicos quando se fala em formação leitora na infância é o texto literário infantil. E a principal (inter) ação com esse objeto é a leitura. No entanto, observando a produção editorial voltada a esse público, podemos perceber que o contato com o livro literário infantil captura primeiro o olhar e propicia também o brincar.

O presente estudo procura discutir a interação com o texto literário infantil cuja produção gráfica-editorial privilegia e possibilita o olhar, o brincar e o ler. Para isso, 
apresentamos duas pesquisas que tiveram como objeto diferentes modalidades de produção gráfica-editorial, o livro-brinquedo e o livro de imagem, e que procuraram investigar a produção de sentido a partir da interação com esses objetos, explorando suas possibilidades lúdicas e visuais.

Iniciamos definindo ações relevantes na produção de sentido a partir do texto literário infantil: olhar, brincar e ler. Após explicitar nossas concepções, apresentaremos a análise de duas obras, um livro-brinquedo e um livro de imagem. Essas análises identificam alguns dos efeitos de sentido desses textos, procurando demonstrar como a interação leitora ultrapassa o ler e possibilita ainda o brincar.

Por fim, traremos uma breve discussão sobre essa nova perspectiva de formação leitora que, diante da produção gráfico-editorial voltada ao público infantil, não se restringe à compreensão do funcionamento do sistema alfabético, mas se torna simultaneamente uma experiência de desenvolvimento da sensibilidade e da ludicidade.

\section{Olhar, brincar e ler}

A literatura infantil em seu desenvolvimento histórico, graças aos avanços das tecnologias de impressão, pode ser caracterizada pela associação entre as linguagens verbal e visual. No entanto, diante de alguns livros pertencentes a esse gênero, nós leitores, não importando a idade, muitas vezes somos convidados não apenas a folhear suas páginas, vendo as imagens, desvendando o texto verbal que ele apresenta, mas a interagir de outras maneiras. Conforme Oliveira (2001, p. 5), "ver e olhar são então os dois pólos visados por todos os estrategistas de nossa visão (...). Objetivando a visão, os demais sentidos são convocados para atuarem juntos a fim de despertar a percepção do sujeito."

Esse convite é bastante explícito diante da produção gráfica-editorial contemporânea que propõe diferentes modos de contagiar, provocar ou seduzir o leitor e a torná-lo sujeito de diversas ações para compreender de maneira mais ampla o texto que tem à sua frente. Conforme Cademartori (2009, p. 51): 
A produção literária, deste início de século, mostra acentuada inclinação para transcender as fronteiras de gênero e também para estabelecer novas relações entre imagens e palavras. As ilustrações abandonaram o modesto papel de ficar a serviço do que relatam as palavras e passaram a constituir um outro texto.

As imagens são consideradas, então, um texto que articula formas e cores num determinado suporte através de certa materialidade para produzir uma significação. $E$ o desafio do leitor, ao significá-las, está em desconstruir tais textos imagéticos diferenciando seus elementos e em reconstruí-los, identificando as relações que seus elementos criam. A esse respeito Oliveira $(2001$, p. 6) ressalta que:

Da desmontagem de qualquer imagem o visado é a sua remontagem, a fim de estabelecer como a significação é edificada. Em termos dessa construção, uma imagem, uma semiótica plástica, é formada no plano da expressão pelo material e as matérias que lhe dão existência visiva (formantes matéricos); por pontos, traços, linhas, figuras, formas (formantes eidéticos); cores e cromatismos (formantes cromáticos); uma certa localização das matérias, formas e cores em dada ordenação em um suporte (formantes topológicos).

O interesse do leitor está, pois, em compreender "como a imagem mostra o que mostra." (OLIVEIRA, 2001, p. 6). E para tal é preciso analisar não só o seu conteúdo, mas as qualidades sensíveis em termos de cores, formas, espaços e materialidades, como também o modo delas se articularem para produzir um significado. Na interação com qualquer texto, seja verbal ou não verbal, importa as relações que o leitor apreende entre o conteúdo do que é mostrado e o modo como esse conteúdo se expressa.

Essa ampliação no modo de interagiar com o texto literário infantil reflete-se na maneira como definimos o objeto. $O$ texto literário infantil passa a ser, em grande parte das publicações, texto-imagem e texto-palavra que se articulam para constituir um único enunciado a ser estabelecido por meio do ler e do olhar. A leitura passa a ser não somente a interação com o verbal ou com a imagem, mas uma experiência de olhar para o objeto livro, considerando a sua constituição matérica e discursiva. Conforme Linden (2011, p. 9):

Ler um livro ilustrado é também apreciar o uso de um formato, de enquadramentos, da relação entre capa e guardas com seu conteúdo; é também associar representações, optar por uma ordem de leitura no espaço da página, [...]. Ler um livro ilustrado depende certamente da formação do leitor. 
Além disso, diferentes publicações literárias infantis reforçam, cada vez mais, a caracterização da imagem como texto único que constitui a obra, não apenas como ilustração, alegoria ou enfeite, mas como elemento expressivo e discursivo, exigindo do leitor um olhar atento ao que vê. Esses livros constituídos apenas por imagens, conhecidos como livros de imagem ou livros álbum ou livros sem palavra, têm o seu texto apresentado única ou exclusivamente por imagens, revelando um conteúdo discursivo a partir de elementos visuais que provocam o olhar diante dos elementos sensíveis - cor, forma, espaço, materialidade - para que a leitura aconteça.

A provocação decorrente das imagens não pode ser encarada apenas sob a ótica do narrar, mas precisa ser considerada também como um convite para experimentar um olhar fruidor, conhecedor, decodificador e crítico para o modo de expressão dessa narrativa, num claro exercício de "leitura de imagens" (BARBOSA, 2010), no qual o leitor se permite "envolver estésica e sensivelmente (...) para depois analisar, entender os modos como [elas] nos tocam, nos provocam e provocam outros modos de ver, de sentir e de pensar" (PILLAR, 2011, p. 2).

Outro tipo de publicação, os livros-brinquedos, instigam diferentes sentidos além do olhar e convocam ações do leitor. Essas obras associam à leitura do elemento alfabético ao olhar das imagens, bem como provocam diversas sensações e colocam o leitor numa posição mais próxima do livro, ao solicitarem sua participação para além do virar a página. São livros que convidam o leitor a abrir e fechar abas, a escutar sons emitidos pelo próprio livro, a sentir aromas ou a tocar em elementos a partir de pop-ups que saltam das páginas.

Essa maior interatividade implica diversas maneiras de ler e evidencia grandes inovações nas produções de literatura infantil do nosso século. Tais inovações nos livros acompanham as que chegam todos os dias aos jogos, aos computadores e outras tecnologias, chamando a atenção para o objeto livro e suas possibilidades interativas. Assim, a relação do leitor com o texto literário passa a envolver exercícios de olhar, a leitura dos textos visual e verbal e momentos de brincar. Estamos, portanto, diante de um objeto sincrético tanto pela sua constituição discursiva quanto pela oportunidade interativa oferecida. 
A definição de sincretismo que adotamos é a da semiótica discursiva, a qual considera texto sincrético aquele que apresenta mais de um plano de expressão ${ }^{1}$, para um único conteúdo, estabelecendo um todo de sentido (FIORIN, 2009). Podemos caracterizar o texto literário infantil, constituído por palavra e imagem, como um objeto sincrético. Essa caracterização se dá em decorrência de se tratar de um texto que "aciona várias linguagens de manifestação" (GREIMAS \& COURTÉS, 2008, p.467) relevantes na produção de sentido.

No texto literário infantil, palavras e imagens, linguagem verbal e linguagem visual, associam-se para estabelecer um sentido, cada uma delas constitui uma parte do texto, revelando conteúdos expressos por seus elementos - verbais ou visuais -, que se superpõem e criam um conteúdo discursivo único. Diante de um texto literário infantil, temos uma pluralidade de substâncias expressivas - verbais e visuais - unidas para estabelecer um único conteúdo.

A pluralidade expressiva além de resultar em uma semiótica sincrética, possibilita também uma interação estésica com o texto. O leitor não apenas decodifica e compreende o elemento alfabético que apresenta o verbal, não apenas olha e compreende o elemento sensível que constitui a imagem, mas toca, sente, brinca com essa imagem que se esconde com abas ou salta da página em pop-ups. A interação do leitor com o livro-brinquedo torna-se uma experiência sensível e inteligível, que envolve um olhar atento, a brincadeira e a leitura dos textos verbal e visual. Essa experiência depende de como o texto se mostra ao leitor, de como ele busca interagir com ele, algo que pode se dar exclusivamente pela imagem que convida o leitor a olhar, brincar e ler.

\footnotetext{
1 A teoria semiótica discursiva considera que toda linguagem é constituída por dois planos que se complementam numa relação de pressuposição recíproca para produzir uma significação: o plano da expressão, que abriga as qualidades sensíveis de cada linguagem, e o plano do conteúdo, que diz respeito ao discurso, ao significado. "Um nível da expressão e um nível do conteúdo como em qualquer outra manifestação de linguagem constroem essa significação. Encontram-se esses dois níveis interligados de tal forma, que se pode dizer que conteúdo é forma e forma é conteúdo. Inseparáveis, as individuações desses são metodológicas e o tratamento deles permite uma desmontagem da imagem, que é via de acesso para se depreender como a significação é produzida por um certo uso da linguagem, um dado emprego de estratégias selecionadas para produzir, pela organização textual da imagem, determinados efeitos de sentido". (OLIVEIRA, 2001, p. 6)
} 
Essa experiência interativa com o livro-brinquedo, um objeto normalmente voltado ao público ainda não-leitor da palavra, em processo de alfabetização, possibilita ao leitor em formação aproximar-se desse livro e interagir com ele a partir de suas competências de leitura. Com o livro-brinquedo, exercita-se o olhar, brincase de ler, brinca-se enquanto lê. O leitor tem a oportunidade de viver por meio da brincadeira experiências que "reproduzem muito mais do que viram" (VIGOTSKI, 2009, p. 17), seja por ainda ser criança e as experiências pertencerem ao mundo dos adultos ou por serem práticas distantes da sua realidade.

Com o livro de imagem, a experiência de olhar possibilita além do desenvolvimento sensível diante dos elementos visuais, também o exercício criativo de brincar de criar possíveis sentidos para o que se encontra figurativizado nas páginas. "Olhá-las é, então, muito mais do que adentrar numa história é, sobretudo, aceitar fazer parte de uma experiência vivificante intensa comandada pelo sensível e pelo inteligível que, ininterruptamente, insiste em nos convidar a aderir. (OLIVEIRA, 2001, p. 7)

Diante da imagem, formas se apresentam ocupando o espaço com suas cores, materializando a narrativa por meio do visual. Posteriormente, em textos que tenham a presença apenas do verbal a materialização visual se dará na esfera de uma imagem interna, cognitiva. O livro de imagem enriquece o reportório visual do leitor para futuros exercícios de imaginação. "Graças aos múltiplos suportes das várias manifestações de linguagem, essa visibilidade permanece, nos permitindo deslocamentos de nosso tempo-espaço aos de eras remotas e aos de eras futuras". (OLIVEIRA, 2001, p. 5)

Esses objetos de leitura levam-nos a compreender 0 ato de ler como uma ação múltipla, pois permitem diferentes modos de apreensão dos efeitos de sentido através do olhar, do brincar, do ler. Assim, a leitura não se reduz à interação com o sistema alfabético na sua forma escrita. Ler assume o papel de "preencher uma lacuna em nossa vida", possibilitando uma expansão "sensorial, emocional ou racional, de uma vontade de conhecer mais" (MARTINS, 2006, p. 82). Ler torna-se um ato interativo e crítico ao mesmo tempo, uma compreensão "que não se esgota na decodificação pura 
da palavra escrita ou da linguagem escrita, mas que se antecipa e se alonga na inteligência do mundo" (FREIRE, 2005, p. 11).

\section{Na floresta do bicho-preguiça: um livro para se surpreender e brincar ${ }^{2}$}

O livro "Na floresta do bicho-preguiça", de Sophie Strady, conta a história de uma floresta que está sendo desmatada e precisa de cuidados. O bicho-preguiça é um personagem que aparece como parte integrante dessa floresta e vivencia os acontecimentos que vão ocorrendo ao longo da história.

O livro tem formato de um retângulo vertical estreito, mais comprido do que largo. Esse formato não é tão comum nos livros, mas é bastante eficiente quanto ao manuseio pela criança, visto que, por ele ter uma largura menor, há a possibilidade de que a criança o abra por completo sem perder o domínio. Todos esses fatores contribuem para que a leitura e fruição das imagens sejam feitas de modo tranquilo pela criança.

Sua capa e contracapa são tomadas por árvores, mas essas não são representadas de uma forma usual. A primeira vista temos a ideia de que vários círculos verdes foram pintados em um fundo branco, nesses círculos foram feitas texturas em diferentes formatos, como se retirassem a tinta verde deixando aparecer o fundo branco. Algumas copas de árvores ganham bolinhas, outras formatos de gotas, algumas delas são mais ovais e outras são tão pequenas que parecem riscos mais grossos. A grande magia acontece quando não olhamos para esse conjunto em separado, mas quando olhamos o todo temos a impressão de que essas partes brancas nas árvores são os espaços entre as folhas, ou ao contrário que as partes brancas são as folhas e o verde a floresta.

Quando abrimos o livro, encontramos no verso da capa uma página toda marrom com uma borda em que a ilustração da capa se estende. Nessa página, temos as informações técnicas e algo que chama a atenção, no canto inferior esquerdo, um

2 Este texto integra a pesquisa Para entender o livro-brinquedo: arte e literatura na infância (EVALTE, 2014) realizada com bolsa de Mestrado do Conselho Nacional de Desenvolvimento Científico e Tecnológico (CNPq). 
texto que diz: "Este livro foi impresso com tinta de soja ecológica sobre o papel feito a partir de florestas com gestão florestal responsável".

O tema do livro, o uso da tinta ecológica e do papel produzido a partir de fontes responsáveis vem contribuir com pensamentos que afloravam no ano de 2011, o ano de publicação da obra. Nesse ano, a Organização das Nações Unidas (ONU) declarou como Ano Internacional das Florestas, para justamente pensarmos em ações sustentáveis visando a preservação dos pulmões do planeta: as florestas.

Na página seguinte, existem duas cores de fundo: uma é uma mancha verde, que representa a floresta de forma rasteira como grama e pequenas plantas; a outra é a cor branca, que aparece nos quatro cantos das páginas (utilizando como referência a página dupla). As árvores que compõem a floresta têm as mesmas características daquelas da capa do livro, mas aqui elas estão colocadas de maneira que sobressaem da página em "3D". Há também uma linha grossa azul, que figurativiza um rio que atravessa a floresta, ao cortar as duas páginas. Em meio às árvores da floresta, quando olhamos de perto, vemos araras vermelhas e azuis, tucanos azuis e amarelos e também o bicho-preguiça, que está pendurado em uma das árvores. O texto verbal aparece no canto inferior da página direita, um local em que se toca para virar as páginas.

A história começa falando sobre o sossego e a tranquilidade que é a floresta e, em seguida, o narrador faz uma provocação ao leitor: - E o bicho preguiça - você consegue vê-lo? Na edição francesa também há a pergunta; - Et le paresseux - le vois-tu?

Essa convocação ao leitor para procurar um personagem tem características parecidas com livros como "Onde está Wally?" que começaram a ser publicados no Reino Unido em 1987, e chegaram ao Brasil em 1992. Esses livros tinham como personagem principal um menino chamado Wally, ele estava sempre escondido no meio da multidão, seja em viagens a diversos lugares ou até mesmo em páginas cheias de figuras. Wally era caracterizado sempre da mesma forma, isso ajudava na hora de procura-lo. Na leitura de livros infantis é possível encontrar similaridades não 
só nas histórias, mas também, no seu formato e no modo de interação com o leitor. Muitas vezes o ilustrador ou escritor se utiliza de práticas observadas em outros livros infantis, pois já conhece a recepção do público para esse tipo de estratégia.

Ao virar a página vemos uma máquina em meio as árvores, ela possui uma parte comprida e reta com uma serra circular na ponta, essa parte se sobressai de onde estão as árvores, deixando aparecer apenas a serra por cima da floresta. No texto, temos a descrição de que as máquinas estão destruindo a floresta e, com o barulho, os pássaros estão fugindo. Novamente é perguntado ao leitor se sabe onde está o bicho-preguiça? O texto refere que ele continua no mesmo lugar, sonhando e que não ouve nada.

Quando passamos para próxima página o fundo branco toma conta e apenas um pequeno espaço do verde ainda continua na parte central das duas páginas. Nesse espaço ainda há uma fileira de árvores intacta e é onde está o bicho-preguiça. O rio, figurativizado antes por uma linha grossa azul que passava por entre a floresta, agora é apenas uma fina linha que se interrompe em algumas partes do caminho.

Uma máquina carregadeira tem na ponta de sua haste um formato de uma garra cheia de galhos e folhas. Mais duas máquinas, também carregadeiras, uma está carregando várias toras de madeira e colocando em um caminhão que já está repleto delas; a outra está rodeada de toras. Atrás da fileira das máquinas temos duas fileiras, também em "3D", com algumas árvores, muitos bichos de cor marrom e figuras humanas, também da mesma cor, somente os pássaros são retratados nas cores laranja, amarelo, azul e vermelho. A cor marrom utilizada mostra a silhueta de animais e humanos, possibilitando depreender que eles eram parte daquele lugar, como a terra é parte da floresta.

Quando viramos a página, vemos que o branco tomou conta de quase todo o fundo, no centro das duas páginas (na dobra central do livro) resta um pequeno círculo de fundo verde, com uma árvore projetada para fora das páginas e é justamente nela que está pendurado o bicho-preguiça. Uma máquina carregadeira está a ponto de 
pegar essa árvore. Em torno da árvore há vários troncos, galhos e marcas de roda marrom em meio ao fundo branco.

O traço azul, que figurativiza um rio, está muito fino e já não está mais tão comprido quanto antes. Agora, ele se transformou em três pequenas linhas azuis no imenso branco da página. $O$ texto refere que restou apenas uma árvore e pede que o bicho-preguiça acorde para fugir.

Ao virarmos a página, o plano de fundo branco toma conta do que antes era uma grande floresta verde, tudo que resta são pequenos galhos na página esquerda. No canto superior dessa página, temos o texto, que agora é maior e se dedica a falar de como é triste o que aconteceu com a floresta. Fala de um homem que, como nós (leitores), também lamenta o que aconteceu e decide plantar uma floresta.

A surpresa acontece quando vemos que existe uma aba para ser puxada, nessa mesma página, nela há o desenho de um homem semeando, quando puxamos devagar essa aba ela vai levantando pequenos brotos verdes, de árvores e de plantas, que vão aparecendo em meio ao fundo branco da página direita. Em um dos pequenos brotos está pendurado o bicho-preguiça.

A parte final do texto, que agora está na página esquerda, diz do trabalho que o homem teve para reconstruir o solo e a floresta, dos primeiros brotos se rompendo e também mostra que o bicho-preguiça está de volta e retoma a pergunta: "Olha lá, você consegue vê-lo"?

Assim, durante a história, a todo momento, somos levados a procurar onde está o bicho-preguiça. Há uma oposição baseada na relação de sumir e aparecer, esconder e achar que instiga o leitor, ao virar cada páginas, a entrar nessa brincadeira, a qual se enriquece com o trabalho dos engenheiros do papel na construção de uma floresta em pop-up. Podemos dizer que tanto o bicho-preguiça como a floresta participam dessa mesma relação de aparecer e sumir, já que, ao iniciar a história a floresta é grande e cheia de vida e no decorrer da história ela vai desaparecendo até sumir por completo, mas depois reaparece ao final. 
Através das imagens, das interações propostas ao leitor e do texto verbal o livro mostra a história do desmatamento de uma floresta e suas consequências, alude ao poder dos humanos de destruir, também ao poder de preservar e restaurar o meio ambiente.

\section{Zoo: um livro para olhar e brincar}

Zoo é um livro de imagem que tem a autoria de Jesús Gabán (2012). Caracterizamos essa obra como livro de imagem, por duas razões (NUNES, 2013). A primeira razão é baseada na análise visual da obra por meio da qual não identificamos a presença do verbal sendo a imagem o elemento essencial para a produção de sentido. A segunda explicação é baseada na compreensão de que a imagem é "uma unidade de manifestação auto-suficiente, como um todo de significação, capaz de ser submetido à análise" (GREIMAS \& COURTÉS, 2008, p.254), o que torna a imagem elemento central para a leitura desse livro.

A leitura nessa obra é um convite ao olhar atento e curioso - como se espera que seja o de um visitante de um zoológico. O leitor, no entanto, não visitará um zoológico comum, terá sim a oportunidade de se deparar com diferentes grupos de animais em seu habitat natural apresentado ao longo das páginas.

A brincadeira ou o jogo de olhar, e também de ser olhado, inicia na capa. $O$ título da obra - um modo abreviado de se referir ao zoológico ou a versão dessa palavra em língua inglesa -, sobreposto em um fundo de cor branca, destaca-se em fonte regular, com tamanho grande e na cor preta, como uma espécie de playground para os animais que interagem com as letras que o compõem. Um tucano e um quati ocupam a letra Z, um bicho preguiça carregando seu filhote está pendurado na letra $\mathrm{O}$, enquanto uma girafa faz a outra letra $\mathrm{O}$ de colar. Todos os olhares dos animais se voltam para o leitor da capa, alguns de maneira mais direta, como o do quati e do bicho-preguiça e sua cria, de quem só vemos a pequena cabeça, todos numa atitude de convocação para olhar e ser olhado. Com relação às cores que constituem os animais, predominam os tons pastéis e terrosos, no quati, no bicho-preguiça e na girafa, em contraste com o colorido do bico e das plumas do peito da arara que se 
destaca pousada no topo da letra Z. Ela tem seu bico e cabeça voltados para a girafa, mas o olhar encara o leitor.

Assim como nós, leitores, somos olhados atentamente pelos animais, podemos ter a mesma atitude em relação a eles, essa é a provocação da capa. A girafa, não apenas pelo seu tamanho, instiga essa atitude atenta do leitor, mas também pelo seu olhar emoldurado por longos cílios e pelas manchas de seu corpo, mais um sinal do brincar de olhar ou do tentar descobrir o que se esconde. Um olhar mais atento revela que as manchas em tons de marrom, presentes no corpo da girafa sugerem ao leitor outros animais - tartaruga, porco, raposa, rato, canguru, golfinho, etc. -, como se o corpo da girafa fosse palco para um teatro de sombras ou fosse um zoológico no qual o leitor pode ver diferentes animais.

A produção de sentido nessa obra evidencia o jogo de ideias opostas, que dá início ao percurso gerativo de sentido ${ }^{3}$ proposto pela semiótica discursiva. Desde a capa e ao longo das páginas, são apresentados diferentes pares opostos: animais terrestres e aéreos, com pescoço longo ou curto, com cauda longa ou curta, com bico ou sem; o grafismo das letras em oposição à figurativização assumida por elas a partir da presença dos animais que interagem com elas. Para esse texto, destacamos algumas páginas para uma análise mais atenta, procurando descrever os possíveis efeitos de sentido que podem ser identificados nesse jogo de oposição que dá início ao percurso gerativo de sentido.

Na primeira dupla de páginas, encontramos com um grande quati em primeiro plano, atrás dele árvores com longos galhos em frente a uma pequena cerca. Entre os galhos das árvores e no chão intercalados com os troncos, outros animais se distribuem: urso panda, raposa, rato, etc. Alguns voltam seu olhar para o leitor assim

3 O percurso gerativo de sentido "é uma representação dinâmica da produção de sentido, é a disposição ordenada das etapas sucessivas pelas quais passa a significação para se enriquecer e, de simples e abstrata, torna-se complexa e concreta". (FLOCH, 2001, p. 15) Neste percurso podemos identificar três níveis: o fundamental, que trata das oposições sobre as quais o sentido se organiza e das relações entre esses termos; o narrativo, em que se organiza a narratividade, o encadeamento de situações e ações, com participantes que desempenham papéis determinados, a partir do ponto de vista de um sujeito; e o discursivo, é aquele em que a narrativa é recoberta por termos que lhe dão concretude, relativas à constituição das pessoas ou à actorialização, do espaço e do tempo do discurso. (FIORIN, 2001, p. 15-40) 
como o quati, outros, de perfil, tem o seu olhar voltado em outra direção. Pensando sobre o jogo de semelhanças e diferenças da capa, o jogo de olhar nos leva a perceber que todos os animais dispostos ao longo dessa dupla de página têm o olhar ou seus olhos como elemento de destaque, são olhos grandes ou emoldurados por cores escuras - marrom ou preto - em contraste com o restante do pelo que reveste seus corpos. Ainda como desafio para o olhar, o leitor diante dessa dupla de página pode se deparar com outro aspecto misterioso que convoca a sua curiosidade, ou seu instinto de descobrir. No canto esquerdo inferior, deparamo-nos com um menino, vemos seus ombros, sua cabeça na qual se destacam seus olhos ampliados pelo uso de um binóculo. O que o menino quer ver melhor? Serão os animais? Ou ele deseja se parecer com os animais que vê? Perguntas que poderão instigar o leitor a olhar com mais atenção, assim como talvez pretenda fazer o menino.

Haverá algum mistério ou convite para olhar semelhante nas páginas seguintes, será essa a estratégia visual que se destaca nessa obra?

Viramos a página e nosso encontro agora é com um grande rinoceronte, de pele acinzentada. Pelo modo com que a cor preenche o corpo do grande animal que quase ocupa por completo a dupla de páginas de um lado a outro, podemos perceber que estamos diante de uma pele grossa, com diferentes texturas. Não apenas pelo tamanho, ou pela cor, o rinoceronte é destacado nessa dupla de páginas também pelo contraste com o plano de fundo da cena constituído por pequenos montes de terra cujos topos possuem um pequeno prédio revelando uma espécie de vilarejo com seus altos e baixos. Além do rinoceronte, outros animais compõem a cena. Borboletas coloridas voam em torno do rinoceronte, abaixo dele vemos um pequeno tatu e na página à direita, abaixo da cabeça do rinoceronte encontramos um pequeno cascudo sobre uma pedra, como se quisesse alcançar o rinoceronte. Podemos ainda ver, no canto inferior direito, uma espécie de escorpião e à direita no canto, encontramos o menino que assim como nós leitores espia a cena, usando um capacete.

No jogo de olhar, o que há de comum e de diferente, qual o mistério a ser visto pelo leitor nessa cena descrita? Como ideias opostas temos o peso do rinoceronte em contraste com a leveza das borboletas. E como ideias semelhantes, a couraça do 
rinoceronte próxima do tatu, do cascudo e do escorpião, revelando uma característica comum desses animais que é copiada pelo menino através do capacete que veste para também ter em seu corpo, mesmo que artificialmente, um tipo de couraça protetora.

Assim, o leitor a cada cena, a cada dupla de páginas depara-se com um novo grupo de animais que propõe um jogo, instigando o olhar a buscar oposições e similaridades entre os animais e, também, a descoberta de onde está o menino, e como ele procura uma semelhança com os animais que, assim como nós leitores, ele observa atentamente. O menino é o fio condutor desse passeio vivido também pelo leitor. A partir da identificação das oposições semânticas pertencentes ao nível fundamental do percurso gerativo de sentido, o leitor pode estabelecer as relações entre os animais apresentados e o menino que se esconde entre eles.

O nível narrativo é aquele que qualifica os sujeitos actantes da narrativa animais e menino. O menino busca a conjunção com os animais, assumindo uma de suas características que pode ser identificada em todos. Essa conjunção, no entanto, não é plena.

E o nível discursivo dessa narrativa visual diz respeito à concretude das oposições em temas e figuras quanto ao tempo, ao espaço e à actorialização.

A cada dupla de página coloca diante do leitor um grupo de animais com características semelhantes e diferentes, revelando um contraste, e simultaneamente esconde entre esses animais um menino que tenta de alguma forma fazer parte do grupo, algo que pode ser entendido como um modo de apresentar o mundo com seus contrastes e seus modos de encontrar pertencimento. Entendemos que se trata de um sentido bastante avançado para ser construído por um leitor ainda em formação, mas ele não é único. O essencial é diante dessa obra o leitor se permitir brincar de olhar, ler na medida da sua compreensão carregando consigo essa experiência e os sentidos construídos para outras leituras. 


\section{Considerações finais}

Diante do que apresentamos, é possível perceber que, na atualidade, pensar em formação de leitor é pensar para além da alfabetização do verbal. A partir da demanda de diferentes meios e modos de interação decorrentes da proximidade com os dispositivos tecnológicos contemporâneos que compõem nossas vidas, a educação e as ações nela implicadas acabam por se contagiarem e buscarem novos meios e modos para a sua promoção. Destacamos dentre essas ações educacionais, a leitura e a formação de leitores. Ações que precisam se modificar para serem capazes de lidar com os objetos desenvolvidos pelas editoras que investem, em grande proporção, em algo que chame a atenção das crianças, seja pelo uso de multimídia na constituição do objeto livro, ou pelo uso de personagens conhecidos, de recursos sensoriais - imagens, abas, sons, aromas - na tentativa de continuar capturando um público tão estimulado por outros meios de seu cotidiano multimidiático.

Contudo, é preciso estarmos atentos para que a experiência da leitura não se perca nessa voracidade e diversidade interativa. A interatividade e a exploração sensorial proporcionadas pela leitura desses livros literários infantis precisam de tempo, não ocorrem na rapidez que elas por vezes trazem implícitas. A leitura não pode se tornar um vertiginoso desvendar de segredos que logo torna o livro obsoleto. As inventividades gráficas e visuais oferecidas pelos livros precisam ser encaradas como um meio de vivenciar a leitura na contramão da aceleração cotidiana, em um exercício de olhar atento e sensível (EVALTE e NUNES, 2015) capaz de possibilitar não a reprodução do mundo, mas primordialmente, a criação de um novo mundo.

Dessa maneira, entendemos como importante, em nosso contexto atual, a mediação desses livros na escola. Essa mediação precisa acontecer compreendendo os efeitos de sentido que podem emergir desses objetos e como eles podem ser explorados na formação desse leitor interativo e criativo, que olha, brinca e lê o livro. 


\section{Referências}

BARBOSA, Ana Mae Tavares Bastos. A imagem no ensino da arte: anos 1980 e novos tempos. 8.ed. São Paulo: Perspectiva, 2010.

EVALTE, Tatiana Telch. Para entender o livro-brinquedo: arte e literatura na infância. Dissertação (Mestrado em Educação) - Faculdade de Educação, Universidade Federal do Rio Grande do Sul, Porto Alegre, 29/07/2014, $122 f$.

EVALTE, Tatiana Telch; NUNES, Marília Forgearini. Livro-brinquedo e livro de imagem: a literatura infantil como objeto de leitura da imagem no contexto escolar. In: Encontro da Associação Nacional de Pesquisadores em Artes Plásticas, 24, 2015, Santa Maria/RS, Anais [recurso eletrônico] do $24^{\circ}$ Encontro da Associação Nacional de Pesquisadores em Artes Plásticas. Santa Maria/RS: Associação Nacional de Pesquisadores em Artes Plásticas; Universidade Federal de Santa Maria, PPGART; Universidade Federal do Rio Grande do Sul, PPGAV, 2015, p.2914-2927. Disponível em: $<$ http://anpap.org.br/anais/2015/simposios/s5/tatiana_evalte_marilia_nunes.pdf>. Acessado em: 26 de agosto de 2017.

FIORIN, José Luiz. Para uma definição das linguagens sincréticas. In: OLIVEIRA, Ana Claudia de; TEIXEIRA, Lúcia (Orgs.). Linguagens na comunicação: desenvolvimentos da semiótica sincrética. São Paulo: Estação das Letras e Cores, 2009, p.15-40.

FIORIN, José Luiz. Elementos para análise do discurso. São Paulo: Contexto, 2001.

FLOCH, Jean-Marie. Alguns conceitos fundamentais em Semiótica Geral. Documentos de Estudo do Centro de Pesquisas Sociossemióticas. São Paulo: Centro de Pesquisas Sociossemióticas, 2001. (tradução de Quelques concepts fondamentaux em sémiotique générale. In: _. Petites mythologie de l'oeil et de l'esprit pour une sémiotique plastique. Paris: Éditions Hadès-Benjamins, 1985. p. 189-207.)

FREIRE, Paulo. A importância do ato de ler: em três artigos que se completam. 46.ed São Paulo: Cortez, 2005.

GABÁN, Jesús. Zoo. Porto Alegre: Editora Projeto, 2012.

GREIMAS, Algirdas Julien; COURTÉS, J. Dicionário de semiótica. São Paulo: Editora Contexto, 2008.

LINDEN, Sophie Van der. Para ler o livro ilustrado. Tradução de: Dorothée de Bruchard. São Paulo: Cosac Naify, 2011.

MARTINI, Augusto. A simplicidade das coisas. Publicado em 22 de dezembro de 2011. Disponível em: $<$ http://asimplicidadedascoisas.wordpress.com/2011/12/22/natal-algumas-curiosidades-sobre-a-datae-os-simbolos-natalinos-parte-2>. Acessado em: 13 de abril de 2017.

MARTINS, Maria Helena. O que é leitura. 19.ed. São Paulo: Brasiliense, 2006.

NUNES, Marília Forgearini. Leitura mediada do livro de imagem no ensino fundamental: letramento visual, interação e sentido. Tese (Doutorado em Educação), Faculdade de Educação, Universidade Federal do Rio Grande do Sul, Porto Alegre, 2013.

OLIVEIRA, Ana Claudia de. Lisibilidade da imagem. Revista da FUNDARTE / Fundação Municipal de Artes de Montenegro, Montenegro, v.1, n.1, p. 5- 7, jan. /jun. 2001.

PILLAR, Analice Dutra (Org.). A educação do olhar no ensino das artes. Porto Alegre: Mediação, 2014.

PILLAR, Analice Dutra. Visualidade contemporânea e educação: interação de linguagens e leitura. Contrapontos (On-line), Itajaí, v. 13, n.3, p. 178-185, 2013. Disponível em: <http://www6.univali.br/seer/index.php/rc/article/view/4773/pdf_4>. Acessado em: 14 de maio de 2017.

PILLAR, Analice Dutra. Apontamentos para leitura de desenhos animados e videoartes. In: GERALDO, Sheila Cabo, COSTA, Luiz Cláudio da (ORG.). Anais do $20^{\circ}$ Encontro da Associação Nacional de Pesquisadores em Artes Plásticas. Rio de Janeiro: ANPAP, 2011. p. 1-15. Disponível em: <http://www.ufrgs.br/gearte/artigos/artigo_analice02.pdf>. Acessado em: 26 de agosto de 2017. 
STRADY, Sophie. Na floresta do bicho-preguiça. Trad. Cássia Silveira. Ilustrador Louis Rigaud. São Paulo: Cosac Naify, 2011.

VIGOTSKI, L. S. O papel do brinquedo no desenvolvimento. In: A formação social da mente. Org. Michael Cole et al. Trad. José Cipolla Neto, Luís Silveira Menna Barreto, Solange Castro Afeche. 6.ed. São Paulo: Martins Fontes, 1998, p. 121-137.

VIGOTSKI, L. S. Criação e imaginação. In: Imaginação na infância: ensaio psicológico: livro para professores. Trad. Zoia Prestes. São Paulo: Ática, 2009, p. 11-18.

\section{Marília Forgearini Nunes}

É Licenciada em Letras, com habilitação nas línguas portuguesa e inglesa e respectivas literaturas (UFSM,1999), Especialista em Língua Inglesa (PUCRS, 2000), Especialista em Supervisão Escolar (PUCRS-PUCVirtual, 2005), Mestre em Letras (UNISC, PPGL, 2007) e Doutora em Educação (UFRGS, PPGEDU, 2013) com pesquisa financiada pelo CNPq. Professora Adjunta A na Universidade Federal do Rio Grande do Sul, atuando no Departamento de Ensino e Currículo, da Faculdade de Educação, na área de Formação pedagógica e linguagem. Docente no Programa de Pós-graduação em Museologia e Patrimônio. Pesquisadora do Grupo de Pesquisa em Educação e Arte (GEARTE/CNPq) e do Grupo de Estudos e Pesquisas em Linguagem e Alfabetização (GEALFA). Editora Associada da Revista GEARTE. Pesquisa os seguintes temas: mediação, formação leitora, literatura infantil, letramento literário e visual, leitura da imagem a partir da semiótica discursiva.

E-mail: mariliaforginunes@gmail.com

Currículo: http://lattes.cnpq.br/5561310307931640

\section{Tatiana Telch Evalte}

Doutoranda em Educação pelo Programa de Pós-Graduação em Educação na UFRGS, com orientação da prof. ${ }^{\text {a }}$ Dra. Analice Dutra Pillar. Bolsista de Doutorado CAPES. Possui Mestrado em Educação pelo Programa de Pós-Graduação em Educação da UFRGS, na linha de pesquisa Educação Arte Tecnologia, concluído no ano de 2014 sob a orientação professora Dra. Analice Dutra Pillar.Tem formação em Licenciatura Plena em Pedagogia pela Universidade Federal do Rio Grande do Sul, concluída no ano de 2010. Atualmente participa de pesquisas na área de semiótica discursiva sob coordenação da professora Dra. Analice Dutra Pillar. Participa do Grupo de Educação e Arte (GEARTE). Faz pesquisas na área da Semiótica Discursiva. Participa como editora assistente no periódico online Revista GEARTE.

E-mail: tatitelch@yahoo.com.br

Currículo: http://lattes.cnpq.br/4190365170162102

\section{Analice Dutra Pillar}

É Professora Titular da Faculdade de Educação da Universidade Federal do Rio Grande do Sul, Bolsista de Produtividade em Pesquisa do CNPq. Possui graduação em Artes Plásticas pela Universidade Federal do Rio Grande do Sul (1983), mestrado em Artes pela Universidade de São Paulo (1990) e doutorado em Artes pela Universidade de São Paulo (1994). Realizou Estágio de PósDoutorado em Artes na Facultad de Bellas Artes da Universidad Complutense de Madrid, Espanha. Atua como professora na graduação e no Programa de Pós-Graduação em Educação da Faculdade de Educação da UFRGS, orientando Mestrado e Doutorado na área de Educação e Artes Visuais. Tem experiência nas áreas de Educação e de Artes, com ênfase no Ensino de Artes Visuais, atuando principalmente nos seguintes temas: formação de professores, artes visuais, leitura da imagem, produções audiovisuais, mídia televisiva e infância.

E-mail: analicedpillar@gmail.com

Currículo: http://lattes.cnpq.br/0033345213407184

Recebido em 9 de setembro de 2017 Aceito em 20 de março de 2018 